\title{
Noble Gas Mass Spectrometry in Earth and Planetary Sciences
}

\author{
Rainer Wieler*
}

\begin{abstract}
Noble gases are very rare elements in most relevant samples in geochemistry and cosmochemistry. Noble gases may perhaps also look rather boring to chemists, as they do not form any stable compounds. However, it is precisely their rarity and chemical inertness which makes noble gases versatile elements in a very wide range of fields, such as oceanography, climatology, environmental sciences, meteorite studies, rock dating, early solar system and early Earth history, and many others. Mass spectrometry is by far the main analytical tool in noble gas geochemistry and cosmochemistry, partly because the rarity of noble gases often allows researchers to recognize in the same sample different noble gas 'components' of different origin and hence different isotopic composition. This contribution attempts to illustrate the wide range of applications of noble gas mass spectrometry in the Earth sciences with selected examples.
\end{abstract}

Keywords: Cosmochemistry $\cdot$ Geochemistry $\cdot$ Mass spectrometry $\cdot$ Noble gases

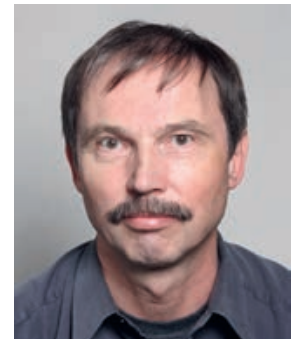

Prof. Rainer Wieler studied physics at ETH Zürich and obtained his doctoral degree on noble gases in lunar samples at the Department of Earth Sciences of ETH under the guidance of Prof. P. Signer. From 1994 he led the Laboratory for Noble Gas Cosmochemistry and Geochemistry at ETH until his retirement in 2014. He was promoted to Titularprofessor in 2000. He is a Fellow of the Meteoritical Society and Asteroid (6366) Rainerwieler has been named in his honour.

\section{Noble gas analysis}

Noble gas mass spectrometry in Earth and Planetary sciences differs in several aspects from other gas mass spectrometry techniques. This is due to two fundamental properties of the noble gases: they are 'noble', i.e. they do not form (stable) compounds, and they are (very) rare in most environments, hence their alternative name 'rare' gases. The second property requires a high detection efficiency, which in most cases implies 'static' mass spectrometry. This means that valves to vacuum pumps need to be closed before noble gases from a sample are let into the mass spectrometer. In contrast, stable isotopes of gases such as $\mathrm{H}, \mathrm{N}$, or $\mathrm{O}$ are usually analyzed in 'dynamic' mode, i.e. gas is continuously fed into the mass spectrometer whose valves to vacuum pumps remain open, allowing for fast switching between sample and standard gas. The 'nobility' of noble gases facilitates static analyses, because the background levels of chemically active gases such as $\mathrm{H}_{2}, \mathrm{CH}_{4}$, $\mathrm{H}_{2} \mathrm{O}, \mathrm{CO}, \mathrm{CO}_{2}$, etc. can be kept low by binding or adsorbing them onto chemical getters, e.g. metals such as $\mathrm{Zr}$, Ti or alloys thereof.

Fast switching between standard and sample gas is not possible in static mode, which is one reason why the precision of isotope ratio measurements for noble gases is usually lower (typically not better than a few per mill) than what can be achieved for traditional stable isotope gas mass spectrometry. However, the precision of a noble gas analysis anyway is often governed by the available sample size, hence ion counting statistics, and by blank

${ }^{*}$ Correspondence: Prof. R. Wieler, E-Mail: wieler@erdw.ethz.ch

ETH Zürich, Department of Earth Sciences, Clausiusstrasse 25, CH-8092 Zurich or spectrometer 'memory' corrections. 'Memory' means gas from previous analyses released during a later measurement. This notwithstanding, the extreme rarity of noble gases in the environment is the decisive factor for the very low detection limits for noble gases, which may be just a few hundred atoms for rare isotopes. Argon-40 may serve as an example, although it has one of the highest detection limits among the noble gas isotopes. This isotope is constantly produced by the radioactive decay of ${ }^{40} \mathrm{~K}$ with a half-live of $1.27 \mathrm{Ga}$. Yet, although only $\sim 10 \%$ of the decaying ${ }^{40} \mathrm{~K}$ end up as ${ }^{40} \mathrm{Ar}$ atoms, while $\sim 90 \%$ are converted to ${ }^{40} \mathrm{Ca}$, the potassium-argon method is one of the most widely used age dating techniques in the geosciences, whereas potassium-calcium dating has found only niche applications. This is because the abundance of $\mathrm{Ca}$ in rocks exceeds that of Ar by many orders of magnitude.

Another major characteristic of noble gas geo- and cosmochemistry is that in most cases one also is interested in measuring gas amounts, unlike for many other elements, for which often only isotope ratios are of interest. One reason for this is that the intrinsic rarity of noble gases often allows one to detect in the same sample noble gases of several 'components', produced or trapped by particular processes. An example are interactions of high-energy cosmic ray particles with target atoms in a meteorite. Such 'cosmogenic' noble gases are easily detectable, while resulting isotopic shifts in other elements are extremely minor.

Because noble gas mass spectrometry is a rather minor discipline in Earth- and Planetary sciences, often requiring specialized skills and equipment, for a long time researchers such as John Reynolds in Berkeley ${ }^{[1]}$ built their own instruments. Today, however, most laboratories rely on commercial spectrometers offered by several companies. Gases are commonly ionized by electron impact, with electron acceleration voltages on the order of $100 \mathrm{~V}$. The standard mass separation technique uses a variable electromagnetic sector field, as pioneered by A. O. Nier, ${ }^{[2-4]}$ but high-voltage scanning or other techniques like quadrupole mass filters are also used. Ions are collected either by Faraday cups, electron multipliers or Daly detectors. Multiple detectors may allow simultaneous detection of different isotopes. Relatively small and inexpensive quadrupole mass spectrometers are often used for gas concentration measurements but are also becoming popular for isotope ratio measurements. ${ }^{[5,6]}$ In some cases, a quadrupole instrument is also used in combination with a sector field instrument, the former to determine gas amounts, the latter isotope ra- 
tios. Calibration of spectrometer sensitivity and mass discrimination is mostly done by peak-height comparison with a separate analysis of a standard gas mixture of known amount and isotopic composition. Alternatively, a gas strongly enriched in a particular isotope can be added to the sample gas. This does not require an independent calibration run and is mostly used when the accurate amount of gas in a sample is of primary interest, e.g., for $\mathrm{K}-\mathrm{Ar}$ dating. More details about analytical techniques in noble gas mass spectrometry are given in refs $[7,8]$.

A crucial task in most noble gas analyses is the extraction of the gases from a sample, followed by their purification, i.e. the removal to the extent possible of chemically active volatile species $\left(\mathrm{H}_{2}, \mathrm{CH}_{4}, \mathrm{H}_{2} \mathrm{O}, \mathrm{CO}, \mathrm{CO}_{2}\right.$, etc. $)$. In many cases, the different noble gases $(\mathrm{He}-\mathrm{Xe})$ are separated from each other and analyzed sequentially. More often than not, gas extraction and cleaning systems are tailored to a laboratory's specific needs, reflecting the wide diversity of sample types and scientific problems. Noble gases are found in solid samples, in fluids, as trace constituents in gas mixtures, trapped in ice or sediments, etc., with sample masses ranging from, e.g., subnanogram-sized presolar grains up to kilograms of ice. Gases are extracted in ultra-high vacuum systems by heating samples, either in furnaces or by lasers and perhaps in different temperature steps, by crushing rocks, by intense shaking of water-filled containers, by melting of ice, etc. Given this diversity, a 'standard' noble gas extraction and purification system does not exist. Examples can be found in overview volumes ${ }^{[7,9,10]}$ and many specific publications, some of which will be referred to below. As an example, Fig. 1 shows the line presented by Stanley et al.[11] for noble gas analysis in water samples. Progress in the miniaturization of mass spectrometers ${ }^{[12]}$ also results in developments of portable mass spectrometry systems in Earth and environmental sciences, allowing, e.g., analyses of noble gases and biogeochemically active gases directly in the field. ${ }^{[13]}$ The immediate availability of such data may greatly facilitate proper sample collection and reduce field-work logistics.

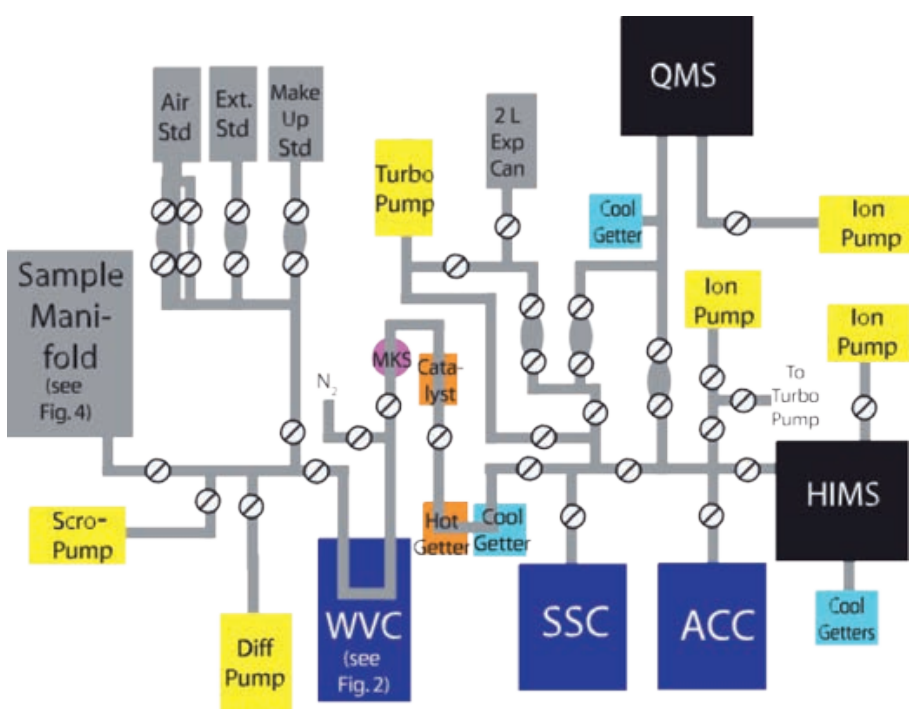

Fig. 1. Schematic of gas processing and analysis line for noble gas measurements in water samples presented by Stanley et al. ${ }^{[11]}$ HIMS is a sector field mass spectrometer for He isotopes, QMS a quadrupole mass spectrometer for the other noble gases. WVC, SSC, and ACC are three different cryotraps used to trap water and to separate the different noble gases prior to analyses. Figure courtesy of American Geophysical Union and Geochemical Society.
In the following, I will discuss a few major applications of noble gas mass spectrometry in Geochemistry and Cosmochemistry and the implications of these data for Earth and Planetary Sciences. I will start with work on extraterrestrial samples, ranging from meteorites to comets, the latter studied, e.g., by mass spectrometers on space missions. A fundamental understanding of the noble gas inventories of the Earth's interior and atmosphere also requires insights into how the early Earth acquired its noble gases from the solar accretion disk and its building blocks.

\section{Noble Gases in Cosmochemistry}

Many meteorites - the so-called undifferentiated meteorites or chondrites - have a remarkable property: the abundances of most elements agree quite closely with their abundances in the Sun. For a very rare chondrite class, elemental abundances are identical to solar values to within mostly $10-20 \% .{ }^{[14]}$ This is excellent evidence that undifferentiated meteorites broadly represent matter accreted during solar system formation. The most remarkable exception are the noble gases. Especially the light noble gases are many orders of magnitude less abundant in meteorites than in the Sun. Expressed in atoms per atom, the He abundance in the Sun is about $8 \%$, that in meteorites typically on the order of a tenth of a ppm or less. For the very rare Xe, the difference is much smaller, abundances being roughly $1 \mathrm{ppb}$ in the Sun and up to $\sim 3 \times 10^{-2} \mathrm{ppb}$ in meteorites. Their rarity does in no way mean, however, that noble gases in meteorites are not very useful to study early solar system processes. While reading the noble gas record is not easy, the rareness of these elements allows one to recognize processes difficult or impossible to study with other elements, as should become clear in the following.

In meteorites and other solid samples, we distinguish between in situ produced and trapped noble gases. ${ }^{[15]}$ Among the former are the radiogenic gases, e.g., ${ }^{40} \mathrm{Ar}$ from radioactive decay of ${ }^{40} \mathrm{~K}$ (half-life $\left.\mathrm{T}_{1 / 2}=1.27 \mathrm{Ga}\right)$ and ${ }^{129} \mathrm{Xe}$, the decay product of ${ }^{129} \mathrm{I}_{\left(\mathrm{T}_{1 / 2}\right.}$ $=15.7 \mathrm{Ma})$. Another important in situ component are the "cosmogenic' noble gases, produced when high-energy particles of the cosmic radiation interact with atoms in the crystal lattice. The new isotopes usually have a lower atomic mass than the target isotope, e.g. ${ }^{21,22} \mathrm{Ne}$ are produced from ${ }^{24,25,26} \mathrm{Mg}$. Thanks to the intrinsic rarity of noble gases, their cosmogenic fractions are detectable very much easier than those of other stable nuclides. Trapped noble gases have been incorporated into (solid) samples from known or unknown reservoirs by known or unknown processes. Their abundances and isotopic composition allow one to study their source reservoirs, e.g., the Sun (represented by atoms implanted by the 'solar wind'), the early solar nebula (the gas- and dust cloud out of which Sun and planets formed $4.6 \mathrm{Ga}$ ago), or even 'presolar' grains, originating from star generations older than the Sun (Fig. 2). All these different processes are mirrored in a wide variety of noble gas components in meteorites, distinguished by characteristic isotopic and elemental fingerprints in different carrier phases. In the following, I will address a few crucial aspects of radiogenic, cosmogenic, and trapped noble gases in meteorites.

\subsection{Dating by the ${ }^{39} \mathrm{Ar}-{ }^{40} \mathrm{Ar}$ and I-Xe Methods}

Likely the by far best-known application of noble gas mass spectrometry is dating by the K-Ar method, ${ }^{[16]}$ one of the first isotope-based rock dating techniques. Today, the radioactive decay of ${ }^{40} \mathrm{~K}$ to ${ }^{40} \mathrm{Ar}$ is mainly explored by the ${ }^{39} \mathrm{Ar}-{ }^{40} \mathrm{Ar}$ technique, where the concentration of the parent element potassium is determined by irradiating samples with neutrons in a nuclear reactor, thus producing radioactive ${ }^{39} \mathrm{Ar}$ from ${ }^{39} \mathrm{~K}$. Monitor samples of known age are irradiated next to the samples of interest. This allows to determine parent and daughter concentrations with noble gas analyses alone. An even more important advantage is that the technique allows to recognize partial losses of the radiogenic isotope ${ }^{40} \mathrm{Ar}$ by extracting the gas in several steps at increasing sample tem- 


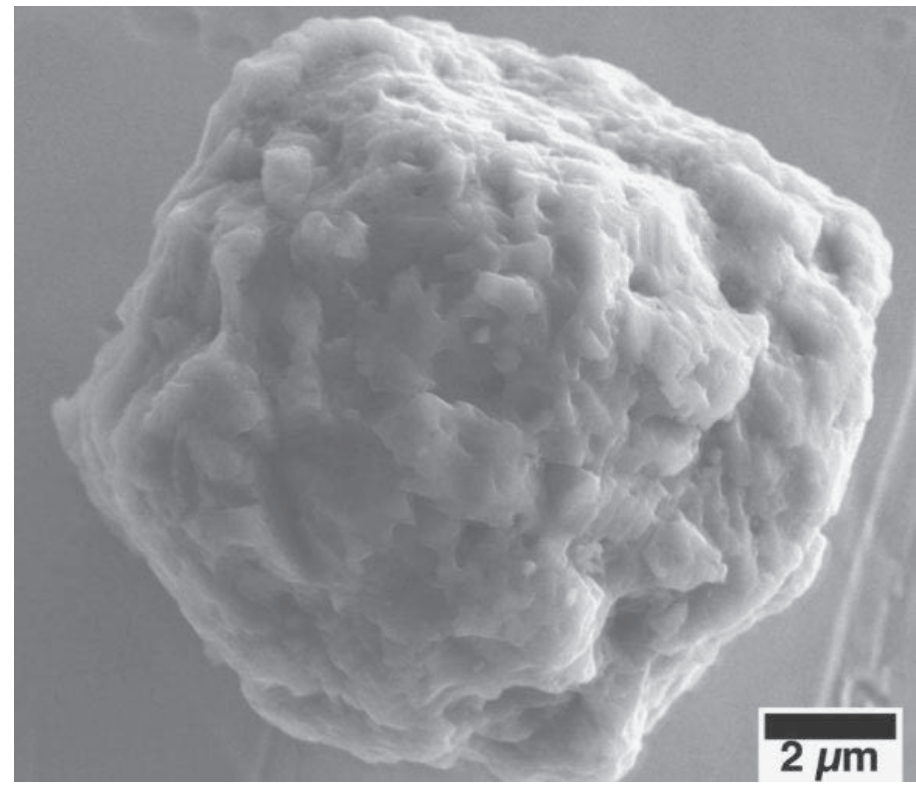

Fig. 2. Presolar silicon-carbide grain extracted from the Murchison meteorite. Presolar grains condense in the cooling envelopes of ancient stars in the final phases of their lifetimes. Some presolar grains are highly resistant against acids and therefore can be extracted by dissolving the bulk meteorite in $\mathrm{HF}$ and $\mathrm{HCl}$. They carry fingerprints of element synthesis processes in their parent star in the form of extreme differences of the isotopic composition of many elements compared to normal solar system compositions. Cosmogenic noble gases in single presolar grains allow to estimate that these grains had been formed between tens of million years up to several billion years before their incorporation into the nascent solar system some 4.6 Ga ago. Figure courtesy of Philipp Heck.

perature. If the ${ }^{40} \mathrm{Ar} /{ }^{39} \mathrm{Ar}$ ratio at low temperatures is relatively low but increases to a plateau value at intermediate to high temperatures, then ${ }^{40} \mathrm{Ar}$ loss, e.g., from low-retentivity sites, can be quantified, and the plateau steps yield the time when ${ }^{40} \mathrm{Ar}$ started to quantitatively accumulate in higher-retentivity sites (Fig. 3). ${ }^{39} \mathrm{Ar}-{ }^{40} \mathrm{Ar}$ dating is one of the most widely used isotopic age dating techniques in Earth sciences (see also the section on Noble Gases in Geochemistry), but it has been developed with meteorites and lunar samples. ${ }^{[17]}$ Ar-Ar studies of lunar samples revealed that lunar lava flows that formed the dark Mare regions were emplaced as early as some $3.9 \mathrm{Ga}$ ago.[18] The Ar-Ar technique is also particularly well suited to date impacts, for example on asteroids, as large impacts led to partial degassing of the radiogenic ${ }^{40} \mathrm{Ar}$, as exemplified in Fig. 3.

Iodine-xenon dating is based on the same principle as ArAr dating. ${ }^{[19]}$ Radioactive ${ }^{129}$ I with a half-live of 15.7 Ma was present in the early solar system as a product of nucleosynthesis in heavy stars near the end of their lives. It decayed into ${ }^{129} \mathrm{Xe}$ within the first approx. $100 \mathrm{Ma}$ of solar system history. Irradiation of meteorite samples in a nuclear reactor converts stable ${ }^{127} \mathrm{I}$ into ${ }^{128} \mathrm{Xe}$ and a Xe analysis in several temperature steps allows to determine a sample's I-Xe age. An important difference to Ar-Ar dating is that the radioactive parent isotope ${ }^{129} \mathrm{I}$ is extinct today. The iodine-xenon system therefore is primarily a relative chronometer, 'only' yielding age differences between events that happened in the first few ten Ma years of solar system history. However, the high temporal resolution of the I-Xe system allows to study this history in exquisite detail. Also, when referenced to a standard meteorite of independently known age (for example based on U-Pb dating), the I-Xe system becomes an accurate absolute chronometer. Below we will see that the radiogenic fraction of ${ }^{129} \mathrm{Xe}$ in the Earth is also of interest to study acquisition and loss processes of the terrestrial atmosphere and mantle.

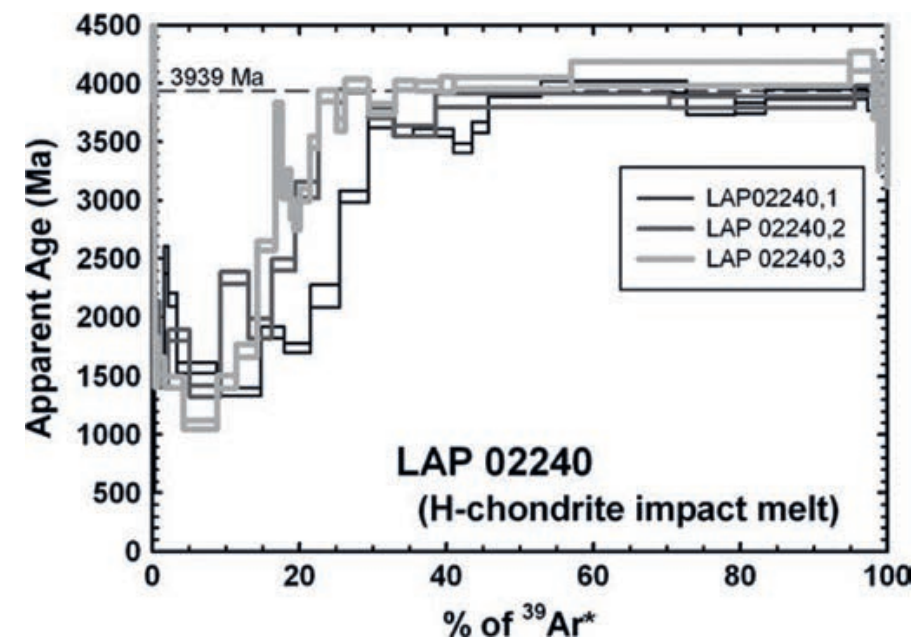

Fig. 3. Apparent ${ }^{39} \mathrm{Ar}-{ }^{40} \mathrm{Ar}$ ages (in million years) of three splits from the same meteorite (impact melt breccia LAP02240) as a function of the fraction of ${ }^{39} \mathrm{Ar}$ produced in a reactor from $39 \mathrm{~K}$ by neutron irradiation. ${ }^{[7]}$ Argon extraction temperature increases from left to right. Low apparent ages at low-T steps indicate a partial resetting of the K-Ar clock by an impact on the meteorite's parent body roughly around 1100 million years ago. 'Plateau ages' at high temperatures around 3940 Ma likely represent the age of the early impact that generated the melt rock. Figure courtesy Wiley.

\subsection{Cosmic-ray Exposure Dating}

Galactic cosmic ray protons and alpha particles $\left({ }^{4} \mathrm{He}\right.$ nuclei) with energies between a few hundred $\mathrm{MeV}$ to a few $\mathrm{GeV}$ penetrate up to a few meters into solid matter. The 'cosmogenic' nuclides produced when the cosmic ray particles interact with atoms of the target rock allow us thus to date the time a meter-sized body (e.g., a meteorite) spent in the interplanetary space from the moment it broke off its parent asteroid upon an impact until it fell onto Earth. ${ }^{[20]}$ In practice, by far the most important cosmogenic nuclides are the noble gases and some radioactive nuclides of suitable half-lives, e.g. ${ }^{10} \mathrm{Be}\left(\mathrm{T}_{1 / 2}=1.38 \mathrm{Ma}\right)$, because of their very low detection limits. Beryllium-10 and other radionuclides such as ${ }^{14} \mathrm{C}$ and ${ }^{26} \mathrm{Al}$ are primarily measured by Accelerator Mass Spectrometry (AMS). [21] Exposure age distributions of different meteorite classes reveal that a large fraction of the meteorites in our collections derive from a few individual collisions in the asteroid belt. For example, Fig. 4 shows that about one out of five meteorites in the world's collections derives from one impact about 7 Ma ago.

With today's computational power, the venerable science of celestial mechanics is strongly improving our understanding of how meteorites find their way to Earth. Cosmic ray exposure age distributions help to provide 'ground truth' to test such theories. In the 1980s it was realized that bodies orbiting in resonance with Jupiter or Saturn will rapidly change their eccentricity in an unpredictable way, and hence may collide with an inner planet within perhaps a million years or less. ${ }^{[22]}$ Such resonances occur, e.g., for meteorites or asteroids at $2.5 \mathrm{AU}$ (1 AU equals the mean distance Earth-Sun), which complete exactly three orbits around the Sun in one Jupiter year. Because these transfer times are much shorter than indicated by the cosmic ray exposure ages of meteorites of typically tens of Ma (Fig. 4), the meteorites must spend most of their lives as small objects in the asteroid belt itself. The 'Yarkovski effect' has been identified as a non-gravitative process driving small bodies slowly into resonant orbits in the asteroid belt by absorption and reemission of sunlight. ${ }^{[23]}$

Cosmogenic nuclides are also important in studying the dynamics of the surface 'regoliths' of planetary bodies. These are a mixture of fine dust, pebbles, and larger rock fragments. A wellknown example is the lunar surface. Samples brought back by the Apollo astronauts revealed that in some locations the top few 


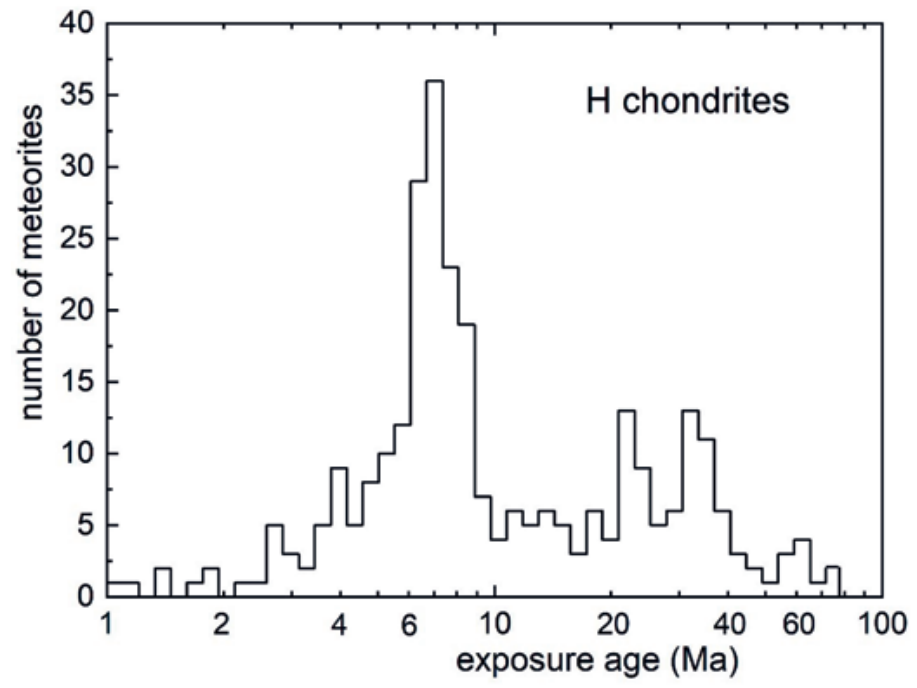

Fig 4. Exposure age histogram of the $\mathrm{H}$-chondrites, one of the major classes of undifferentiated meteorites, representing about $40 \%$ of the meteorites in the world's collections. The data are based on a large number of noble gas cosmic ray exposure ages. ${ }^{[8]}$ As with most other stony meteorite classes, exposure ages of $\mathrm{H}$-chondrites vary between roughly 1-100 Ma. The age distribution shows peaks at $\sim 7,24$, and 33 $\mathrm{Ma}$, indicating large collisional events on the $\mathrm{H}$-chondrite parent body in the asteroid belt between Mars and Jupiter. The very conspicuous peak at $7 \mathrm{Ma}$ encompasses about $45 \%$ of all $\mathrm{H}$ chondrites. Hence, one large collision in the asteroid belt $7 \mathrm{Ma}$ ago is responsible for about $20 \%$ of all meteorites falling to Earth today.

meters of the lunar regolith had remained undisturbed for at least several hundred million years, except for the top few $\mathrm{cm} .{ }^{[24]}$ This is one of the rare studies based on stable cosmogenic nuclides of elements other than noble gases, namely Sm and Gd. Several isotopes of these two elements have extremely large cross sections for the caption of slow secondary cosmic ray neutrons. In 2010 the Japanese Hayabusa mission brought back a small number of grains from the surface of Asteroid Itokawa. The analyses of cosmogenic noble gases in a few of these tiny grains was an analytical challenge, but the data show that the grains had been in Itokawa's surface layer for a few million years only, probably because the asteroid quickly loses material due to its low gravity. ${ }^{[25,26]}$ The planetary science community is eagerly awaiting the first results of new sample return missions, such as the Chinese Chang'e 5, which brought back about $1.7 \mathrm{~kg}$ of material from the Moon and the new asteroid missions Hayabusa 2 and Osiris Rex.

A spectacular type of extraterrestrial samples is the presolar grains (Fig. 2). They formed around stars in the final phases of their life and their extreme isotopic compositions in many elements much improved our understanding of how the chemical elements form during stellar nucleosynthesis. Cosmogenic noble gases in such grains allow to estimate lifetimes of such grains in the interstellar medium before they were incorporated in the gas- and dust cloud out of which our solar system formed.[27] These analyses were done with a special-purpose mass spectrometer developed at ETH Zürich. ${ }^{[28]}$ The instrument very efficiently compresses the sample gas into the ion source with a molecular pump, increasing the sensitivity for $\mathrm{He}$ and $\mathrm{Ne}$ analyses by about two orders of magnitude.

\subsection{Noble Gases Trapped by Extraterrestrial Samples}

Trapped noble gases in extraterrestrial samples represent a bewildering variety of components. The main distinction is between 'solar-like' components with an affinity to the noble gases in the Sun and 'primordial components' which very broadly resemble the noble gases in the terrestrial atmosphere (and those of Mars and Venus). Solar noble gases are abundant, e.g., in the lunar regolith which has been exposed to the solar wind for four billion years. ${ }^{[29]}$ The solar wind is particle radiation emitted by the Sun, with energies leading to implanation depths of a few tens of nanometers. Solar wind noble gases have also been measured at the University of Bern in the aluminum foils exposed on the Moon by the Apollo astronauts ${ }^{[30,31]}$ and later by several groups in targets exposed by the 'Genesis' space mission. An early very important result of the Apollo Solar Wind Composition experiment was the final proof that the D/H ratio in the Earth's oceans and meteorites is about an order of magnitude higher than the protosolar value. ${ }^{[32]}$ Deuterium is converted into ${ }^{3} \mathrm{He}$ in the very young Sun, before hydrogen started to be 'burned' to ${ }^{4} \mathrm{He}$, the energy source of the present Sun. The finding by Geiss and Reeves ${ }^{[32]}$ set new constraints on how the Earth acquired its water and other volatiles.

The Genesis mission sampled ions from the solar wind during about 2 years at a position about 1.5 million $\mathrm{km}$ sunwards from the Earth. ${ }^{[33]}$ In many people's minds this mission was a failure, as the parachutes of its landing capsule did not open, leading to a crash landing. Yet, a large part of the solar wind bearing targets could be recovered, though mostly just as small shards. By now, most of the mission's anticipated goals have been met and partly even exceeded. The elemental abundances and the isotopic composition of all noble gases in the Sun, including the rare $\mathrm{Kr}$ and $\mathrm{Xe}$, are now known with high precision. ${ }^{[34,35]}$ The same is true for oxygen, another crucial element for cosmochemistry, whose solar nebula composition was completely unknown prior to Genesis. The oxygen analysis was particularly challenging, as contamination by terrestrial atmospheric oxygen needed to be completely avoided and also the very minor isotope ${ }^{17} \mathrm{O}$ needed to be analysed with high precision. The solution was found at the University of California in Los Angeles ${ }^{[36]}$ by combining the front part of a secondary ion mass spectrometer (SIMS) with an accelerator mass spectrometer. Crucial auxiliary data were provided by neon measurements. ${ }^{[37]}$ Genesis illustrates the strengths of planetary sample return missions, as progress in cosmochemistry often demands precision only allowed by analyses in terrestrial laboratories. On the other hand, mass spectrometers flown in space allow a much more detailed sampling. For example, the composition of the solar wind as a function of parameters such as speed, sampling window within the solar activity cycle, etc. can be studied in situ in much more detail.

Primordial noble gases in meteorites are important to understand early solar-system processes as well as the noble gas budgets of the Earth and other planets. A general feature of primordial noble gases is their strong depletion of the light noble gases relative to solar abundances. Some primordial noble gases and their presolar carrier grains testify to element synthesis in stars prior to the birth of the solar system, as mentioned in the previous section. The excess of ${ }^{129} \mathrm{Xe}$ provided for the first time clear evidence for the existence of a now extinct radioactive nuclide $\left({ }^{129} \mathrm{I}\right)$ in the early solar system. ${ }^{[38]}$ Iodine- 129 had been produced upon the explosive deaths of massive stars not more than 100 million years before the birth of the solar system. Other 'exotic' noble gas components with very unusual isotopic signatures paved the way to ultimately isolate bona fide presolar grains in meteorites such as the one shown in Fig. 2. Noble gas analyses in single presolar grains are possible but remain challenging. [39]

Mass spectrometers are often also an important part of the suite of instruments flown on planetary exploration missions. For example, they are used to determine the composition of a planetary atmosphere, including its noble gases. A few measurements during the descent in the atmospheres of Venus and Jupiter provided global information on the respective planet. These instruments need to be compact and to consume little energy. An early example was a double-focusing instrument (an electrostatic followed by a magnetic analyzer in a Mattauch Herzog geometry) flown on the Viking I mission to Mars. ${ }^{[40]}$ The instrument had a limited mass 
resolution but provided data on the abundances of $\mathrm{N}_{2}, \mathrm{Ar}$, and $\mathrm{O}_{2}$ in the atmosphere of Mars. These became crucial data to confirm earlier suspicions that a rare class of meteorites (the 'SNC') are from Mars. A few of the SNC contain gas-filled bubbles, verified by the Viking data to represent Martian atmosphere. Later missions to Mars provided more accurate data, including some isotopic compositions, e.g., a quadrupole mass spectrometer on the Curiosity mission. [41] Other isotope ratios in Mars' atmosphere are, however, still only constrained by meteorite data. ${ }^{[42]}$

Spectacular data on the volatile composition of the comet Churyumov-Gerasimenko were provided by the Rosina instrument suite on the Rosetta mission developed at the University of Bern, consisting of a double focusing Mattauch-Herzog mass spectrometer and a time of flight mass spectrometer, allowing analysis of neutrals and ions. ${ }^{[43]}$ From a noble gas perspective, the Xe isotopic composition obtained by the Mattauch-Herzog instrument (Fig. 5) is most remarkable, ${ }^{[44]}$ as it may solve one of the big mysteries of 'xenology'. As will be discussed in the next section, Xe in the Earth's atmosphere is isotopically fractionated relative to the solar composition, with the heavy isotopes enriched in terrestrial $\mathrm{Xe}$. However, the two heaviest isotopes $\left({ }^{134} \mathrm{Xe}\right.$ and ${ }^{136} \mathrm{Xe}$ ) in the atmosphere are less enriched than expected. This means that the formation and evolution of the terrestrial atmosphere is ill-understood. A contribution of Xe from comets during the early history of the Earth is now the leading hypothesis to explain this mystery, because $\mathrm{Xe}$ in Churyumov-Gerasimenko is largely depleted in ${ }^{134,136} \mathrm{Xe}$ relative to Xe in the Sun ${ }^{[44]}$ (see Fig. 6 and following section). If the Xe in Churyumov-Gerasimenko should be typical for comets in general, this would mean that Xe in the comet-forming region in the outer solar system would consist of a different nucleosynthetic mix than the Xe in the inner regions. The challenge would then be to explain how inner and outer regions would have received different Xe contributions from different stellar precursors.

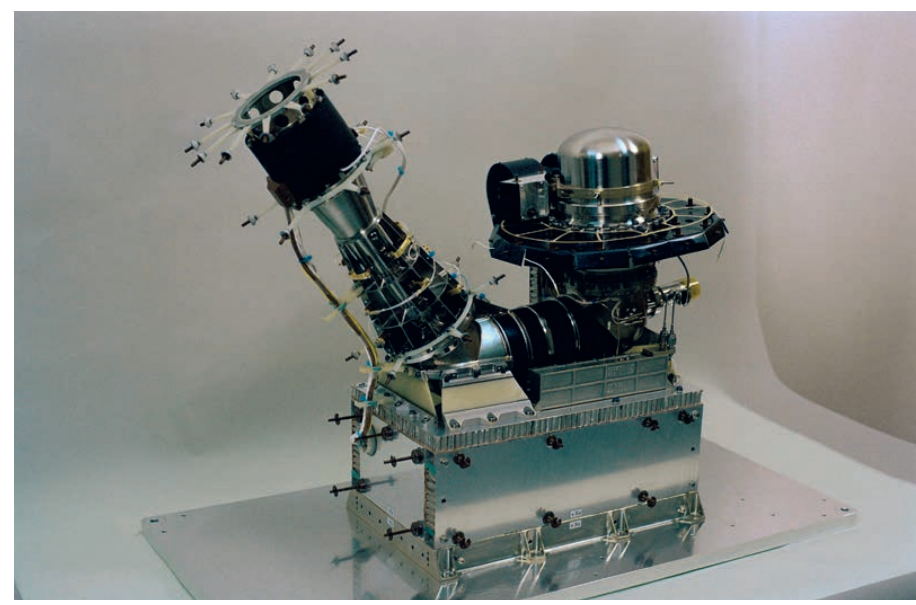

Fig. 5. Double-focusing mass spectrometer for in situ analysis of elemental and isotopic compositions of volatiles emitted by comet Churyumov-Gerasimenko during the Rosetta space mission. ${ }^{[43]}$ This instrument provided, e.g., the isotopic composition data of xenon emitted by the comet (see main text). Size from left to right about $50 \mathrm{~cm}$. Figure courtesy of Springer.

\section{Noble Gases in Geochemistry}

The range of applications of noble gas analyses in the Earth sciences is arguably even wider than in cosmochemistry. Formation ages of rocks or their cooling history, the early and later history of volatile element accretion and losses as well as their fluxes between mantle, crust and atmosphere are some of the major topics. Noble gases are also powerful tracers for many processes in climatology, oceanography, groundwater hydrology, oil, and natural gas exploration, etc. Extraterrestrial He in sediments testifies to environmental changes, induced, e.g., by impacts of asteroids on Earth or large collisions in the asteroid belt. In the following we will once more note how scientific progress and instrumental developments go hand in hand. Examples are the ultrahigh-precision isotopic analyses by dynamic noble gas mass spectrometry, which drives paleoclimate research, the portable mass spectrometry systems allowing analyses in the field, and the extremely sensitive method of counting ultralow amounts of rare noble gas radionuclides by Atom Trap Trace Analysis (ATTA).

\subsection{Dating of Rocks and Thermochronology}

As in cosmochemistry, the probably best known application of noble gases in the Earth Sciences is dating rocks by the K-Ar method, mostly using the ${ }^{39} \mathrm{Ar} /{ }^{40} \mathrm{Ar}$ technique (see Cosmochemistry section). Recent methodical advances and many applications are presented in ref. [17]. The classical book by McDougall and Harrison ${ }^{[45]}$ and the review by Kelley ${ }^{[46]}$ are also recommended. With modern analytical techniques, rock ages as low as 100'000 years can be dated, and in favourable cases the age limit is even considerably lower. ${ }^{[47]} \mathrm{A}$ particular advantage of ${ }^{39} \mathrm{Ar} /{ }^{40} \mathrm{Ar}$ dating is that various potassium-bearing minerals have different and sometimes large ranges of temperatures at which $\mathrm{Ar}$ is retained partially. This makes the system a very useful thermochronometer, allowing to determine not only the time when the K-Ar clock was completely reset, e.g., by forming a rock from a melt or by a large impact, but also to reconstruct its cooling history. Because the temperature near the Earth's surface increases with depth, this allows to study Earth-surface processes and interactions between tectonics, erosion, and climate. ${ }^{[48]} \mathrm{Also}{ }^{4} \mathrm{He}$, the other well-known radiogenic noble gas isotope, has become an important tool in thermochronometry in the past few decades. Helium- 4 results mainly from the radioactive decay chains of $\mathrm{U}$ and $\mathrm{Th}$ into $\mathrm{Pb}$ and was the very first isotope proposed to be used for dating U-rich minerals or even the age of the Earth. ${ }^{[49]}$ However, the method was hardly applied because most minerals lose He already at moderate temperatures over geologic times. This only changed when Zeitler and coworkers ${ }^{[50]}$ proposed to explore this fact to study the thermal history of rocks at low temperatures. In addition to He and Ar, also fission tracks are widely used in thermochronology. ${ }^{[51]}$ Fission tracks are lattice damages in uranium-rich minerals created as a result of the spontanous fission of ${ }^{238} \mathrm{U}$. They can be made visible by chemical etching. At elevated temperatures the tracks progressively shorten and eventually disappear completely at a mineral-specific annealing temperature. Combining the fissiontrack, ${ }^{4} \mathrm{He}-\mathrm{U}-\mathrm{Th}$, and ${ }^{39} \mathrm{Ar}-{ }^{40} \mathrm{Ar}$ techniques allows thus to study the thermal history of samples in the temperature range of $\sim 60-250^{\circ} \mathrm{C}$.

\subsection{Noble Gases in the Earth's Atmosphere and Interior}

Noble gas analyses of samples representing the silicate mantle and the crust of the Earth, such as basalts from mid ocean ridges (plate spreading centers) or oceanic islands like Hawai'i made it clear that the overwhelming part of the Earth's noble gas budget resides in the atmosphere. ${ }^{[52]}$ The easily accessible atmospheric noble gases therefore provide first order information to understand our planet's acquisition of volatile elements from its building blocks (to first order represented by meteorites and comets) or the gaseous solar accretion disk, as well as subsequent loss processes of these elements. Much more difficult to obtain are good constraints on the noble gas budgets of the Earth's interior, a task representing one of the major efforts of present day noble gas geochemistry. Progress again relies on the selection of suitable samples and developments in sampling methods and gas extraction procedures. These should limit to the extent possible contamination of a sample's mantle signatures by atmospheric noble gases. For example, Péron and Moreira ${ }^{[53]}$ released noble gases by 
stepwise crushing a gas-rich 'popping rock'. They collected and stacked the xenon of only those steps showing low atmospheric Ne contamination. This allowed them to obtain a large enough xenon sample for precise isotopic analysis, and to conclude that efficient recycling of volatiles from the atmosphere into the mantle started about three billion years ago.

Radiogenic noble gas isotopes such as ${ }^{40} \mathrm{Ar}$ and ${ }^{129} \mathrm{Xe}$ are not only useful for dating terrestrial and extraterrestrial rocks as discussed above, but also allow us to constrain extent and timing of degassing of the Earth's volatile elements. As a first order conclusion, almost half of the ${ }^{40} \mathrm{Ar}$ ever produced in the Earth's interior has been degassed into the atmosphere, the rest remaining in mantle and crust. In contrast, only about $0.8 \%$ of the total radiogenic ${ }^{129} \mathrm{Xe}$ from the decay of ${ }^{129} \mathrm{I}$ is found in the atmosphere today, and only a small additional fraction remains in the mantle or crust. Because of the short half-life of ${ }^{129} \mathrm{I}$ of $15.7 \mathrm{Ma}$, most of the ${ }^{129} \mathrm{Xe}$ was produced during the first approx. $100 \mathrm{Ma}$ of Earth's history. Therefore, the very small fraction remaining today, together with the almost quantitative retention of ${ }^{40} \mathrm{Ar}$, indicates that the Earth - or partly already its building blocks - almost quantitatively lost its Xe very early on, not later than some $100 \mathrm{Ma}$ after the Earth's formation. ${ }^{[54]}$ One popular idea today is that the Earth was almost completely degassed upon the Giant Impact that formed the Moon. ${ }^{[55]}$ While noble gases provide very important constraints on degassing of the Earth, inferences on other volatiles such as water nevertheless need to be taken with care, as losses of water may have occurred at different epochs than those covered either by ${ }^{129} \mathrm{Xe}$ or ${ }^{40} \mathrm{Ar}$. A $\sim 50 \%$ retention of radiogenic ${ }^{40} \mathrm{Ar}$ does not mean that the Earth also retains about half of its original water budget. ${ }^{[52]}$

Although only little radiogenic ${ }^{129} \mathrm{Xe}$ remains in the Earth's interior, this small fraction reveals much about the accretion and subsequent mixing history of the Earth's mantle. Basalts from oceanic islands (sampling the lower part of the mantle) have lower ${ }^{129} \mathrm{Xe} /{ }^{130} \mathrm{Xe}$ ratios than those from mid ocean ridges which represent the upper mantle. ${ }^{[56]}$ This means that the lower and the upper mantle accreted xenon and other volatile elements from at least two different sources. Neither the Giant Impact nor subsequent mantle convection during more than four billion years completely erased the signature of Earth's heterogeneous accretion provided by its noble gas record. Many details about the sources of Earth's noble gases remain unclear, but the big picture is that the Earth's mantle retains $\mathrm{He}$ and $\mathrm{Ne}$ broadly resembling in its isotopic composition the $\mathrm{He}$ and $\mathrm{Ne}$ in the Sun, whereas the $\mathrm{Kr}$ and the $\mathrm{Xe}$ in the mantle is similar to $\mathrm{Kr}$ and $\mathrm{Xe}$ in primitive meteorites. ${ }^{[57-59]}$ That $\mathrm{He}$ and $\mathrm{Ne}$ predominantly originate from the gaseous solar nebula but $\mathrm{Kr}$ and $\mathrm{Xe}$ predominantly from solid matter is perhaps not so surprising given the largely different relative abundances of light and heavy noble gases in the two different sources.

As noted above, atmospheric Xe cannot be straightforwardly explained as isotopically fractionated solar Xe. This is a long-standing conundrum, as shown in Fig. 6. The abundances of the two heaviest isotopes ${ }^{134} \mathrm{Xe}$ and ${ }^{136} \mathrm{Xe}$ in the atmosphere are lower than expected if $\mathrm{Xe}$ in the Earth's atmosphere would derive from a solar source only. Relative to solar Xe, the abundances of ${ }^{134} \mathrm{Xe}$ and ${ }^{136} \mathrm{Xe}$ are also substantially lower in the comet Churyumov-Gerasimenko. ${ }^{[44]}$ A substantial admixture of such cometary Xe to the Earth on top of isotopically fractionated solar (or meteoritic) Xe could therefore explain the terrestrial Xe isotopic composition. This explanation might solve the terrestrial xenon conundrum, if Xe in ChuryumovGerasimenko would be typical for Xe in other comets and if cometary-like matter would have contributed substantially to the Earth.

\subsection{Noble Gases as Geochemical Tracers}

Noble gases are widely used as chemically (and biologically) inert tracers. An overview of such tracer applications is given in ref. [7]. Here I summarize a few examples.

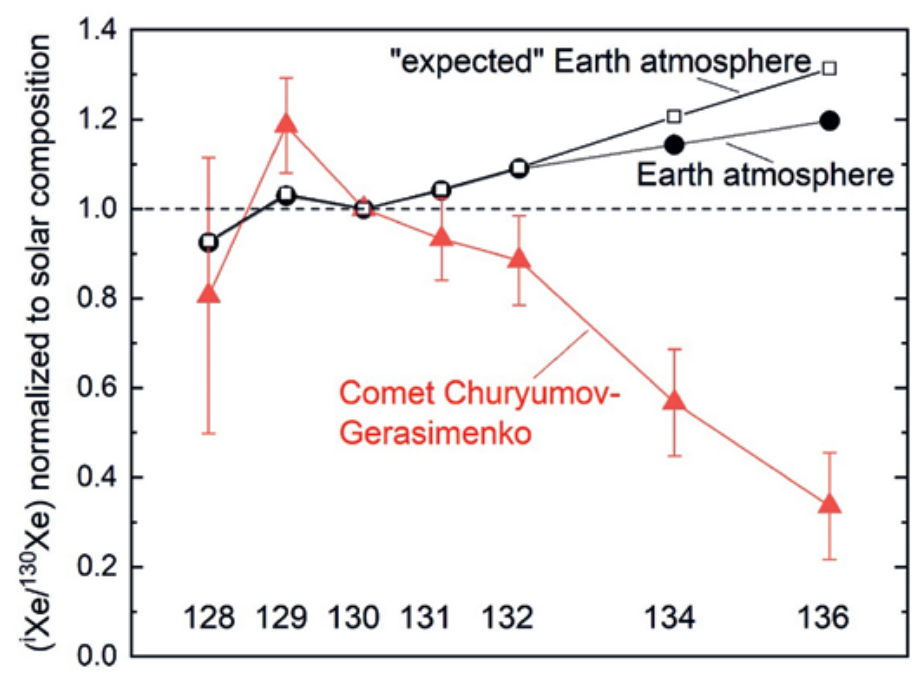

Fig. 6. Xenon isotopic composition of the terrestrial atmosphere (solid circles) and the comet Churyumov-Gerasimenko as measured by the Rosetta mission ${ }^{[44]}$ (red triangles). Isotopic abundances are normalized to solar composition and ${ }^{130} \mathrm{Xe} ;{ }^{124,126} \mathrm{Xe}$ are not shown, as they were not measured in the comet. Isotope numbers are given at the bottom of the figure. Also shown are 'expected' values for the terrestrial atmosphere (open squares), if terrestrial Xe would be derived from solar composition by mass fractionation, as deduced by the four isotopes ${ }^{128,130,131,132} \mathrm{Xe}$. Xenon-129 is affected to variable degree by a radiogenic contribution from ${ }^{129}$ decay, and hence not diagnostic here. The lower than 'expected' abundance of ${ }^{134,136} \mathrm{Xe}$ in the measured atmosphere could be due to a contribution of Xe from comets of the type of ChuryumovGerasimenko.

In oceanography, noble gases are used to study the gas exchange between atmosphere and water, which is crucial to understand the biogeochemical cycle of climatically important gases such as $\mathrm{CO}_{2}$, or the interaction between ocean water and ice.[60] The decay of tritium $\left({ }^{3} \mathrm{H}, \mathrm{T}_{1 / 2}=12.3\right.$ a) to ${ }^{3} \mathrm{He}$ allows to study ocean circulation. ${ }^{[60,61]}$ Most of the tritium in the contemporary oceans derives from the atmospheric nuclear bomb tests in the 1960s. At the ocean surface, He efficiently exchanges with the atmosphere, but once a water parcel is decoupled from the atmosphere, the freshly produced tritiogenic ${ }^{3} \mathrm{He}$ will lead to an increase of the ${ }^{3} \mathrm{He} /{ }^{4} \mathrm{He}$ ratio above the atmospheric value. Two consecutive mass spectrometric He measurements of a water sample (the second one after a few months of storage of the sample degassed upon the first analysis) will thus provide the concentrations of both the radiogenic ${ }^{3} \mathrm{He}$ and its parent ${ }^{3} \mathrm{H}$, yielding a ${ }^{3} \mathrm{H}-{ }^{3} \mathrm{He}$ 'age' of the water parcel. This nominal age may not necessarily be equal to the true time when a water mass was separated from the atmosphere but may also reflect mixing of different water masses. Fig. $7^{[62]}$ shows that tritium concentrations in the Greenland Sea started to decrease below 2000 m ocean depth around 1980, while at the same time nominal ${ }^{3} \mathrm{H}-{ }^{3} \mathrm{He}$ ages start to increase in parallel with time. This reflects a decrease of 'deep water formation' (the sinking of water from surface regions to larger depth) in the North Atlantic at around 1980 due to a reduction of convection flows. Analyses as those shown in Fig. 7 require a very large sample throughput and have triggered automation of noble gas sample preparation and analysis techniques.

Noble gases are also powerful proxies of the Earth's climate history in the relatively recent past. Polar ice cores are the bestknown archives. Air bubbles trapped in cores from Greenland and Antarctica allow to reconstruct the atmospheric concentrations of greenhouse gases such as $\mathrm{CO}_{2}$ and $\mathrm{CH}_{4}$ over the past $800^{\prime} 000$ years. ${ }^{[63]}$ Noble gases from these cores provide a record of the temperature history of the local atmosphere and even the global 
ocean. ${ }^{64]}$ These analyses require much higher accuracies than can be obtained by static noble gas analyses. Hence, much larger sample amounts are needed to allow dynamic isotope ratio mass spectrometry, by alternately feeding standard and sample gases into the mass spectrometer, similar to stable isotope analyses of, e.g., oxygen or nitrogen. Using the gas from about $1 \mathrm{~kg}$ of an ice core, Bereiter et al. ${ }^{[65]}$ achieved isotope ratio precisions of up to 1 ppm per mass unit.

Atmospheric gases are steadily trapped in the 'firn layer', the 50-100 m thick snow layer on top of polar ice sheets. If the mean atmospheric temperature changes with time, a temperature gradient will exist over centuries in the firn layer, which is an excellent thermal insulator. The resulting fractionated air stored in bubbles firmly enclosed in the ice at the low end of
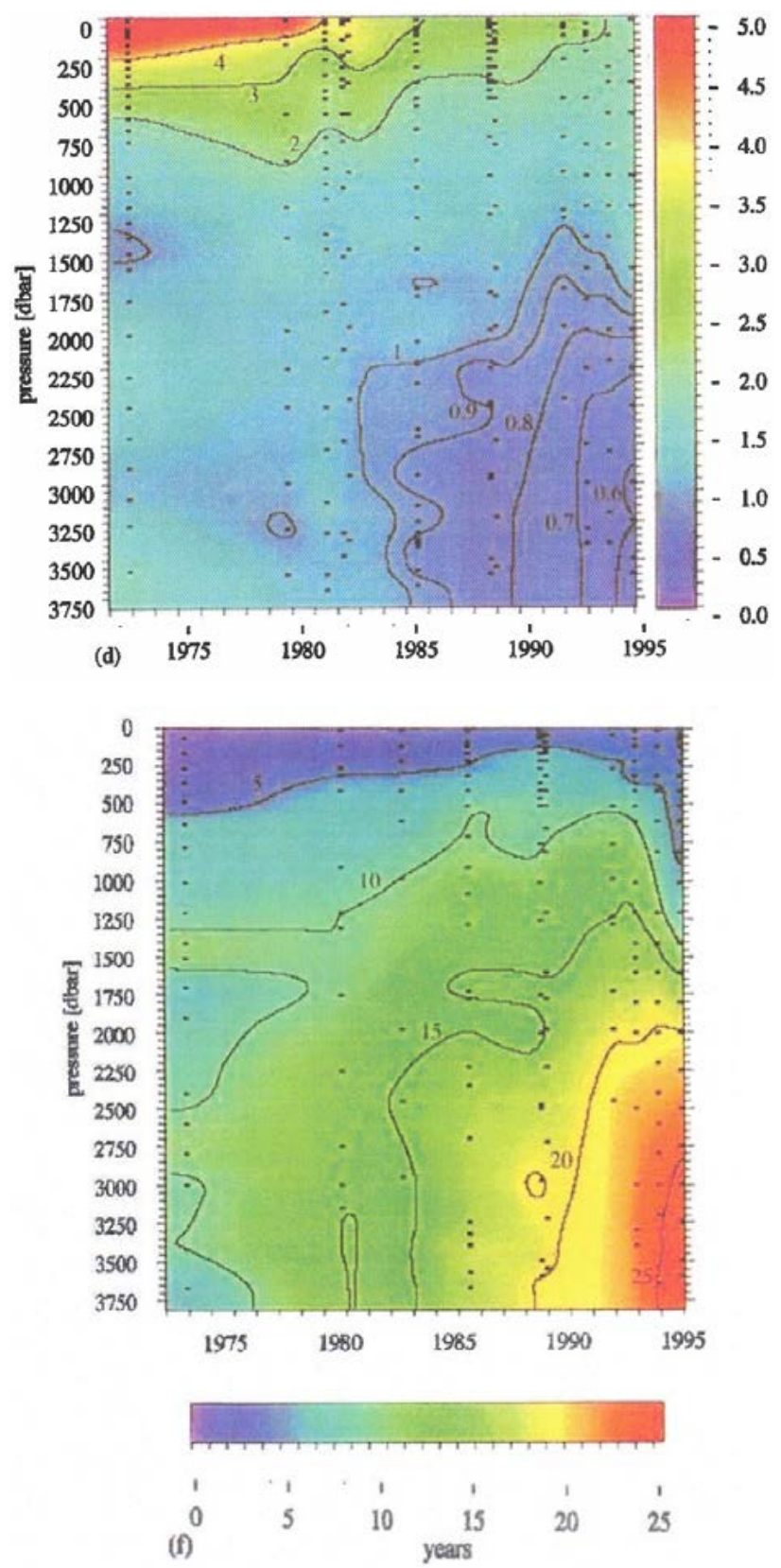

Fig. 7. Tritium concentrations (upper panel) and tritium $-{ }^{3} \mathrm{He}$ ages (lower panel) in the Central Greenland Sea from the sea surface down to 3750 $\mathrm{m}$ depth as a function of time between $\sim 1970-1995 .{ }^{[62]}$ Color-coded T concentrations are given in T-units [1 TU = 1T atom per $1018 \mathrm{H}$ atoms]. Around 1980 tritium concentrations started to decrease below 2000 $m$ while ${ }^{3} \mathrm{H}-{ }^{3} \mathrm{He}$ ages started to increase in parallel with time, reflecting a decrease of deep-water formation (see text). Figure courtesy of American Geophysical Union. the firn layer records the atmospheric temperature changes.[66] Particularly ambitious is the idea to derive past mean ocean temperatures from the elemental abundances of noble gases in air trapped in ice cores. ${ }^{[67]}$ The solubility of noble gases is strongly temperature-dependent, e.g., the concentration of $\mathrm{Xe}$ in water in equilibrium with the atmosphere at $\mathrm{T}=25^{\circ} \mathrm{C}$ is only about half as high as its value at $\mathrm{T}=5{ }^{\circ} \mathrm{C}$. This temperature dependence is much more pronounced for $\mathrm{Xe}$ (and $\mathrm{Kr}$ ) than for the lighter noble gases. A warming ocean will therefore outgas part of its heavy noble gases, thereby altering the elemental abundances of noble gases in the atmosphere. With a suite of 78 samples from an Antarctic ice core, Bereiter and coworkers ${ }^{[67]}$ showed that the mean global ocean temperature increased by about $2.5^{\circ} \mathrm{C}$ over the last glacial transition from $\sim 20,000$ to 10,000 years ago. The data interpretation also required modelling ocean circulation and water exchange between deep and surface water reservoirs. However, the noble gas method pioneered by these authors has the potential to provide information about deep ocean paleotemperatures not unambiguously reflected by the classical paleotemperature proxy, i.e., the oxygen isotopic composition of benthic foraminifera, microorganisms living at ocean floors. ${ }^{[64]}$

The temperature dependence of solubilities of noble gases in water is also used to determine paleotemperatures from archives such as groundwater and speleothems.[68,69] A suitable aquifer will conserve the noble gas concentrations acquired at the interface of atmosphere and groundwater table at the recharge area of the aquifer. If no later equilibration with the atmosphere has occurred, water samples at different positions downstream will record the mean annual soil temperature at the time of groundwater infiltration. Infiltration ages of samples can be determined with ${ }^{14} \mathrm{C}$ or radiogenic noble gas isotopes. In addition to a careful aquifer selection, to assure that sampled water has never been in contact with the atmosphere after infiltration, also gas exchange upon sampling needs to be carefully avoided. Noble gases are particularly suitable recorders of past temperatures because they are insensitive to biological and chemical processes, which often complicate the interpretation of other temperature proxies. The temperature difference between the Holocene and the preceding glacial period has been determined with many aquifers. ${ }^{[70]} \mathrm{A}$ difference on the order of $5-10{ }^{\circ} \mathrm{C}$ had been derived by the noble gas method since the 1970s for mid-northern latitudes on several continents. In contrast, other temperature proxies often suggested considerably lower temperature differences in tropical regions. A new review of many noble gas studies now confirms, however, that also the tropics were significantly cooler by about $6{ }^{\circ} \mathrm{C}$ during the last glacial period, ${ }^{[70]}$ a result which receives significant attention in the paleoclimate community.

Stalagmites are a widely used paleoclimate archive, e.g., using hydrogen and oxygen isotopes. ${ }^{[71]}$ Because the noble gas temperature proxy is independent of other environmental variables, the noble gas paleothermometer can help to improve the understanding of these other isotope records. Progress in noble gas analysis now also allows to use the minute quantities of water stored in fluid inclusions in stalagmites to determine mean annual cave temperatures at the time of inclusion formation. ${ }^{69]}$ Apart from the low noble gas amounts in the typically few mg of water in a suitable sample, a further experimental challenge is the separation of noble gases from fluid inclusions which carry the paleotemperature signal from those in water free inclusions contributing only noble gases with atmospheric composition.

\subsection{Analyses of Very Rare Noble Gas Radionuclides}

Some very rare radioactive noble gas nuclides are valuable tracer isotopes in the geosciences, in particular in hydrology. The most important ones are ${ }^{81} \mathrm{Kr}\left(\mathrm{T}_{1 / 2}=229,000 \mathrm{a}\right),{ }^{85} \mathrm{Kr}\left(\mathrm{T}_{1 / 2}=10.8 \mathrm{a}\right)$, and ${ }^{39} \mathrm{Ar}\left(\mathrm{T}_{1 / 2}=269 \mathrm{a}\right)$. While ${ }^{81} \mathrm{Kr}$ and ${ }^{39} \mathrm{Ar}$ are produced by cosmic rays in the atmosphere, a major source of ${ }^{85} \mathrm{Kr}$ are reprocessing 
plants for spent nuclear fuel. These nuclides are, for example, used to date the subsurface residence time of groundwater, a topic of high societal relevance, as more than 1.5 billion people depend on groundwater as their primary source of drinking water.[72] Concentrations of ${ }^{85} \mathrm{Kr}$ and ${ }^{39} \mathrm{Ar}$ in water samples can be determined by counting their radioactive decays in low-level counting facilities or by accelerator mass spectrometry, but required sample amounts of sometimes tons of water limit their application. ${ }^{[73]}$ The advent of Atom Trap Trace Analysis (ATTA) has the potential to change this. ATTA is an extremely sensitive atom counting method. Neutral atoms of an isotope of interest are trapped in a vacuum chamber using laser beams and then counted by a photo sensor recording their laser-induced fluorescence. ${ }^{[7]}$ The method has the potential to measure ${ }^{81} \mathrm{Kr}$ in a few tens of $\mathrm{kg}$ of water or ice and ${ }^{85} \mathrm{Kr}$ and ${ }^{39} \mathrm{Ar}$ in even considerably smaller samples. ${ }^{75]}$

\section{Conclusions}

Noble gases are an indispensable tool in geochemistry and cosmochemistry and have led to many fundamental insights. Halliday ${ }^{[76]}$ notes that "first discoveries include presolar components in our solar system, extinct radionuclides, primordial volatiles in the Earth, the degassing history of Mars, secular changes in the solar wind, reliable present day mantle degassing fluxes, the fluxes of extraterrestrial materials to Earth, groundwater paleotemperatures and the ages of the oldest landscapes on Earth". Some of these topics have been addressed here and it should have become clear that the chemical inertness and the rarity of noble gases in most environments often make them particularly powerful for many studies. By far the major analytical technique of noble gases in the geosciences is 'conventional' mass spectrometry (as opposed to accelerator mass spectrometry, AMS). 'Conventional' here does not mean, however, that noble gas analytics are in any sense routine. In contrast, most applications require highly specialized equipment and relevant know-how. Even though by now sophisticated noble gas mass spectrometers are offered by several companies, the sample preparation and noble gas extraction and cleaning systems in most cases require individual solutions tailored to specific science goals.

\section{Acknowledgements}

I much appreciate the constructive reviews by Werner Aeschbach and Ingo Leya. I thank Philipp Heck for supplying Fig. 2.

Received: September 14, 2021

[1] J. H. Reynolds, Rev. Sci. Instr. 1956, 27, 928 , https://doi.org/10.1063/1.1715415.

[2] A. O. Nier, Rev. Sci. Instr. 1940, 11, 212, https://doi.org/10.1063/1.1751688.

[3] A. O. Nier, Int. J. Mass Spectrometry 1990, 100, 1.

[4] J. De Laeter, M. D. Kurz, J. Mass Spectrometry 2006, 41, 847, https://doi.org/10.1002/jms.1057.

[5] Y. Sano, N. Takahata, J. Oceanography 2005, 61, 465, https://doi.org/10.1007/s10872-005-0055-x.

[6] B. Schneider, K. Kuiper, O. Postma, J. $\begin{array}{llll}\text { Wijbrans, Quatern. Geochronol. 2009, 4, 508, } & \text {, }\end{array}$ https://doi.org/10.1016/j.quageo.2009.08.003.

[7] 'Advances in isotope geochemistry', Ed. P. Burnard, Springer, Berlin \& Heidelberg 2013, 391pp, https://doi.org/10.1007/978-3-642-28836-4

[8] R. Wieler, in 'Treatise on Geochemistry, 2nd edition', Vol. 15, Analytical Geochemistry/inorganis INSTR. analyses, 2014, p. 355

[9] 'Rev. Min. Geochem.', Vol. 47, Eds. D. Porcelli, C. J. Ballentine, R. Wieler, Mineralogical Soc. America, Geochemical Soc., Washington DC, 2002, p. XVIII + $844 \mathrm{pp}$

[10] T. J. Dunai, 'Cosmogenic nuclides - principles, concepts and applications in the Earth surface sciences', Cambridge Univ. Press, Cambridge, 2010

[11] R. H. R. Stanley, B. Baschek, D. E. Lott, W. J. Jenkins, Geochem. Geophys. Geosyst. 2009, 10, https://doi.org/10.1029/2009gc002429.
[12] P.Mielczarek,J.Silberring,M.Smoluch,Mass SpectrometryRev. 2020,39,453, https://doi.org/10.1002/mas.21614.

[13] M. S. Brennwald, M. Schmidt, J. Oser, R. Kipfer, Environ. Sci. Technol. 2016, 50, 13455, https://doi.org/10.1021/acs.est.6b03669.

[14] K. Lodders, in 'The Oxford Research Encyclopedia of Planetary Science, Oxford University Press 2020, https://doi.org/10.1093/acrefore/9780190647926.013.145.

[15] F. A. Podosek, in 'Treatise of Geochemistry', Vol. 1, Ed. A. M. Davis, 2003 p. 381

[16] F. Jourdan, D. F. Mark, C. Verati, Geological Society, London, Special Publications 2014, 378, 1, http://dx.doi.org/10.1144/SP378.24.

[17] C. M. Merrihue, G. Turner, J. Geophys. Res. 1966, 71, 2852, https://doi.org/10.1029/JZ071i011p02852.

[18] G. Turner, J. C. Huneke, F. A. Podosek, G. J. Wasserburg, Earth Planet. Sci. Lett. 1971, 12, 19, https://doi.org/10.1016/0012-821X(71)90051-3.

[19] C. M. Hohenberg, O. V. Pravdivtseva, Chem Erde-Geochem. 2008, 68, 339, https://doi.org/10.1016/j.chemer.2008.06.002.

[20] R. Wieler, in: The Oxford Research Encyclopedia of Planetary Sciences', Ed. P. Reid, Oxford Univ. Press, Oxford 2021, https://doi.org/10.1093/acrefore/9780190647926.013.142.

[21] W. Kutschera, Adv. Phys. $X \quad$ 2016, $\quad 1, \quad 570$, https://doi.org/10.1080/23746149.2016.1224603.

[22] J. Wisdom, Icarus $\quad \mathbf{1 9 8 3}, \quad 56, \quad 51$, https://doi.org/10.1016/0019-1035(83)90127-6.

[23] W. F. Bottke, D. Vokrouhlicky, D. P. Rubincam, D. Nesvorny, Ann. Rev. Earth Planet. Sci. 2006, 34, 157, https://doi.org/10.1146/annurev.earth.34.031405.125154.

[24] G.P.Russ,D. S. Burnett, G.J.Wasserburg,EarthPlanet. Sci.Lett. 1972, 15, 172 , https://doi.org/10.1016/0012-821X(72)90058-1

[25] K. Nagao, R. Okazaki, T. Nakamura, Y. N. Miura, T. Osawa, K. Bajo, S. Matsuda, M. Ebihara, T. R. Ireland, F. Kitajima, H. Naraoka, T. Noguchi, A. Tsuchiyama, H. Yurimoto, M. E. Zolensky, M. Uesugi, K. Shirai, M. Abe, T. Yada, Y. Ishibashi, A. Fujimura, T. Mukai, M. Ueno, T. Okada, M. Yoshikawa, J. Kawaguchi, Science 2011, 333, 1128, https://doi.org/10.1126/science.1207785.

[26] M. M. M. Meier, C. Alwmark, S. Bajt, U. Böttger, H. Busemann, W. Fujiya, J. Gilmour, U. Heitmann, P. Hoppe, H.-W. Hübers, F. Marone, U. Ott, S. Pavlov, U. Schade, N. Spring, M. Stampanoni, I. Weber, in '45th Lunar and Planetary Science Conference', Lunar and Planetary Institute, Houston, 2014, p. Abstract \#1247.

[27] P.R.Heck,J.Greer,L.Kööp,R.Trappitsch,F.Gyngard,H.Busemann,C.Maden, J.N.Avila,A.M.Davis, R.Wieler,Proc.Natl.Acad.Sci.U.S.A.2020,117,1884, https://doi.org/10.1073/pnas.1904573117

[28] H. Baur, Eos, Trans. Am. Geophys. Union 1999, 46, F1118.

[29] R. Wieler, K. Kehm, A. P. Meshik, C. M. Hohenberg, Nature 1996, 384, 46 , https://doi.org/10.1038/384046a0.

[30] J. Geiss, F. Bühler, H. Cerutti, P. Eberhardt, C. Filleux, Apollo 16 Prelim. Sci. Rep., NASA SP-315 1972, 14.1

[31] J. Geiss, F. Bühler, H. Cerutti, P. Eberhardt, C. Filleux, J. Meister, P. Signer, Space Sci. Rev. 2004, 110, 307, https://doi.org/10.1023/B:SPAC.0000023409.54469.40.

[32] J. Geiss, H. Reeves, Astron. Astrophys. 1972, 18, 126.

[33] D. S. Burnett, Genesis Science Team, Proc Natl. Acad. Sci. U. S. A. 2011, 108, 19147, https://doi.org/10.1073/pnas.1014877108.

[34] V. S. Heber, R. Wieler, H. Baur, C. Olinger, T. A. Friedmann, D. S. Burnett, Geochim. Cosmochim. Acta 2009, 73, 7414 https://doi.org/10.1016/j.gca.2009.09.013.

[35] A. Meshik, C. Hohenberg, O. Pravdivtseva, D. Burnett, Geochim. Cosmochim. Acta 2014, 127, 326, https://doi.org/10.1016/j.gca.2013.11.030.

[36] K. D. McKeegan, A. P. A. Kallio, V. S. Heber, G. Jarzebinski, P. H. Mao, C. D. Coath, T. Kunihiro, R. C. Wiens, J. E. Nordholt, R. W. Moses, D. B. Reisenfeld, A. J. G. Jurewicz, D. S. Burnett, Science 2011, 332, 1528, https://doi.org/10.1126/science.1204636.

[37] V. S. Heber, H. Baur, P. Bochsler, K. D. McKeegan, M. Neugebauer, D. B. Reisenfeld, R. Wieler, R. C. Wiens, Astrophys. J. 2012, 759, 121, https://doi.org/10.1088/0004-637X/759/2/121.

[38] J. H. Reynolds, Phys. Rev. Lett. 1960, 4, 8, https://doi.org/10.1103/PhysRevLett.4.8.

[39] P. R. Heck, S. Amari, P. Hoppe, H. Baur, R. S. Lewis, R. Wieler, Astrophys. J. 2009, 701, 1415, https://doi.org/10.1088/0004-637X/701/2/1415.

[40] A. O. Nier, W. B. Hanson, A. Seiff, M. B. McElroy, N. W. Spencer, R. J. Duckett, T. C. D. Knight, W. S. Cook, Science 1976, 193, 786, https://doi.org/10.1126/science.193.4255.786.

[41] P. R. Mahaffy, C. R. Webster, S. K. Atreya, H. Franz, M. Wong, P. G. Conrad, D. Harpold, J. J. Jones, L. A. Leshin, H. Manning, T. Owen, R. O. Pepin, S. Squyres, M. Trainer, M. S. L. S. Team, Science 2013, 341, 263 , https://doi.org/10.1126/science.1237966. 
[42] U. Ott, T. D. Swindle, S. P. Schwenzer, in 'Volatiles in the Martian Crust' Eds. J. Filiberto, S. P. Schwenzer, Elsevier, Amsterdam 2019, 35, https://doi.org/10.1016/B978-0-12-804191-8.00003-9.

[43] H. Balsiger, K. Altwegg, P. Bochsler, P. Eberhardt, J. Fischer, S. Graf, A. Jackel, E. Kopp, U. Langer, M. Mildner, J. Muller, T. Riesen, M. Rubin, S. Scherer, P. Wurz, S. Wuthrich, E. Arijs, S. Delanoye, J. De Keyser, E. Neefs, D. Nevejans, H. Reme, C. Aoustin, C. Mazelle, J. L. Medale, J. A. Sauvaud, J. J. Berthelier, J. L. Bertaux, L. Duvet, J. M. Illiano, S. A. Fuselier, A. G. Ghielmetti, T. Magoncelli, E. G. Shelley, A. Korth, K. Heerlein, H. Lauche, S. Livi, A. Loose, U. Mall, B. Wilken, F. Gliem, B. Fiethe, T. I. Gombosi, B. Block, G. R. Carignan, L. A. Fisk, J. H. Waite, D. T. Young, H. Wollnik, Space Sci. Rev. 2007, 128, 745, https://doi.org/10.1007/s11214-006-8335-3.

[44] B. Marty, K. Altwegg, H. Balsiger, A. Bar-Nun, D. V. Bekaert, J. J. Berthelier, A. Bieler, C. Briois, U. Calmonte, M. Combi, J. De Keyser, B. Fiethe, S. A. Fuselier, S. Gasc, T. I. Gombosi, K. C. Hansen, M. Hassig, A. Jackel, E. Kopp, A. Korth, L. Le Roy, U. Mall, O. Mousis, T. Owen, H. Reme, M Rubin, T. Semon, C. Y. Tzou, J. H. Waite, P. Wurz, Science 2017, 356, 1069, https://doi.org/10.1126/science.aal3496.

[45] I. McDougall, T. M. Harrison, 'Geochronology and Thermochronology by the ${ }^{40} \mathrm{Ar} /{ }^{39} \mathrm{Ar}$ Method', Oxford University Press 1999, $269 \mathrm{pp}$.

[46] S. P. Kelley, Rev. Mineral. Geochem. 2002, 47, 785, https://doi.org/10.2138/rmg.2002.47.17.

[47] A. Hicks, J. Barclay, D. F. Mark, S. Loughlin, Geology 2012, 40, 723, https://doi.org/10.1130/g33059.1.

[48] P. W. Reiners, T. A. Ehlers, P. K. Zeitler, Rev. Mineral. Geochem. 2005, 58, 1, https://doi.org/10.2138/rmg.2005.58.1.

[49] E. Rutherford, 'Radioactive Transformations', Constable \& Co, London 1906, 287pp.

[50] P. K. Zeitler, Chem. Geol. Isotope Geosci. 1987, 65, 167, https://doi.org/10.1016/0168-9622(87)90071-6.

[51] 'Advances in Fission-Track Geochronology', Eds. P. van den Haute, F. e. De Corte, Springer, 1998, 333 pp, https://doi.org/10.1007/978-94-015-9133-1.

[52] A. N. Halliday, Geochim. Cosmochim. Acta 2013, 105, 146, https://doi.org/10.1016/j.gca.2012.11.015.

[53] S. Péron, M. Moreira, Geochem. Perspect. Lett. 2018, 9, 21, https://doi.org/10.7185/geochemlet.1833.

[54] G. W. Wetherill, Апnи. Rev. Nucl. Sci. 1975, 25, 283 https://doi.org/10.1146/annurev.ns.25.120175.001435.

[55] R. O. Pepin, D. Porcelli, Rev. Min. Geochem. 2002, 47, 191, https://doi.org/10.2138/rmg.2002.47.7.

[56] S. Mukhopadhyay, Nature 2012, 486, 101 , https://doi.org/10.1038/nature11141.

[57] P. Sarda, T. Staudacher, C. J. Allègre, Earth Planet. Sci. Lett. 1988, 91, 73, https://doi.org/10.1016/0012-821x(88)90152-5.

[58] G. Holland, M. Cassidy, C. J. Ballentine, Science 2009, 326, 1522, https://doi.org/10.1126/science.1179518.

[59] M. W. Broadley, P. H. Barry, D. V. Bekaert, D. J. Byrne, A. Caracausi, C. J. Ballentine, B. Marty, Proc. Natl. Acad. Sci. U. S. A. 2020, 117, 13997, https://doi.org/10.1073/pnas.2003907117.

[60] R. H. R. Stanley, W. J. Jenkins, in 'The noble gases as geochemical tracers', Ed. P. Burnard, Springer, Heidelberg, 2013, pp. 55, https://doi.org/10.1007/978-3-642-28836-4_4.

[61] P. Schlosser, G. Winckler, Rev. Mineral. Geochem. 2002, 47, 701, https://doi.org/10.2138/rmg.2002.47.15.

[62] G. Bönisch, J. Blindheim, J. L. Bullister, P. Schlosser, D. W. R. Wallace, J. Geophys. Res.-Oceans 1997, 102, 18553 , https://doi.org/10.1029/97jc00740.
[63] D. Lüthi, M. Le Floch, B. Bereiter, T. Blunier, J. M. Barnola, U. Siegenthaler, D. Raynaud, J. Jouzel, H. Fischer, K. Kawamura, T. F. Stocker, Nature 2008 453, 379, https://doi.org/10.1038/nature06949.

[64] G. Winckler, J. P. Severinghaus, in 'The noble gases as geochemical tracers', Ed. P. Burnard, Springer, 2013 pp. 33 https://doi.org/ 10.1007/978-3-642-28836-4_3.

[65] B. Bereiter, K. Kawamura, J. P. Severinghaus, Rap. Commun. Mass Spectrometry 2018, 32, 801, https://doi.org/10.1002/rcm.8099.

[66] J. P. Severinghaus, E. J. Brook, Science 1999, 286, 930, https://doi.org/10.1126/science.286.5441.930.

[67] B. Bereiter, S. Shackleton, D. Baggenstos, K

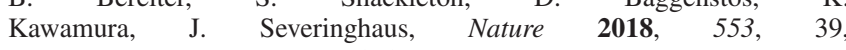
https://doi.org/10.1038/nature25152.

[68] W. Aeschbach-Hertig, D. K. Solomon, in 'The noble gases as geochemical tracers', Ed. P. Burnard, Springer, Berlin \& Heidelberg, 2013, pp. 81, https://doi.org/10.1007/978-3-642-28836-4 5.

[69] M. S. Brennwald, N. Vogel, Y. Scheidegger, Y. Tomonaga, D. M. Livingstone, R. Kipfer, in 'The noble gases as geochemical tracers', Ed. P. Burnard, Springer, Berlin and Heidelberg, 2013, pp. 123 https://doi.org/10.1007/978-3-642-28836-4_6.

[70] A. M. Seltzer, J. Ng, W. Aeschbach, R. Kipfer, J. T. Kulongoski, J. P. Severinghaus, M. Stute, Nature 2021, 593, 228 , https://doi.org/10.1038/s41586-021-03467-6.

[71] S. Affolter, D. Fleitmann, M. Leuenberger, Climate of the Past 2014, 10, 1291 , https://doi.org/10.5194/cp-10-1291-2014.

[72] Z. T. Lu, P. Schlosser, W. M. Smethie, N. C. Sturchio, T. P. Fischer, B. M. Kennedy, R. Purtschert, J. P. Severinghaus, D. K Solomon, T. Tanhua, R. Yokochi, Earth-Sci. Rev. 2014, 138, 196, https://doi.org/10.1016/j.earscirev.2013.09.002.

[73] R. Purtschert, R. Yokochi, N. C. Sturchio, in 'Isotope methods for dating old groundwaters', Eds. A. Suckow, P. K. Aggarwal, L. Araguas-Araguas, IAEA Vienna 2013, 91.

[74] C. Y. Chen, Y. M. Li, K. Bailey, O. C. TP, L. Young, Z. T. Lu, Science 1999, 286, 1139, https://doi.org/10.1126/science.286.5442.1139.

[75] Z. Y. Zhang, F. Ritterbusch, W. K. Hu, X. Z. Dong, C. Y. Gao, W. Jian, S. Y. Liu, Z. T. Lu, J. S. Wang, G. M. Yang, Phys. Rev. A 2020, 101, https://doi.org/10.1103/PhysRevA.101.053429.

[76] A. N. Halliday, Rev. Mineral. Geochem. 2002, 47, v.

[77] T. D. Swindle, C. E. Isachsen, J. R. Weirich, D. A. Kring, Meteorit. Planet. Sci. 2009, 44, 747, https://doi.org/10.1111/j.1945-5100.2009.tb00766.x.

[78] T. Graf, K. Marti, J. Geophys. Res. - Planets 1995, 100, 21247, https://doi.org/10.1029/95JE01903.

\section{License and Terms}

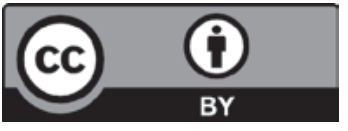

This is an Open Access article under the terms of the Creative Commons Attribution License CC BY 4.0. The material may not be used for commercial purposes.

The license is subject to the CHIMIA terms and conditions: (https://chimia.ch/chimia/about).

The definitive version of this article is the electronic one that can be found at https://doi.org/10.2533/chimia.2022.9 